\title{
Spontaneously disappearing lumbar disc protrusion
}

\author{
Shungu Ushewokunze, Naeem Abbas, Ronan Dardis and Ian Killeen
}

\begin{abstract}
Spontaneous disappearance of a herniated lumbar disc is known to occur. This case study describes a 45-year-old patient whose symptoms of lumbar radiculopathy resolved and follow-up imaging showed complete disappearance of the disc prolapse. This phenomenon strengthens the role of conservative treatment in the management of lumbar disc protrusions.

Keywords

conservative treatment; disappearing disc; lumbar disc protrusion.
\end{abstract}

\section{INTRODUCTION}

Low back pain is a common problem affecting the general population. In $5 \%$ of patients these symptoms are due to lumbar disc protrusions. ${ }^{1}$ Low back pain with sciatica is much more frequently associated with a disc prolapse than low back pain alone. Motor and sensory deficits are present in $50-90 \%$ of patients with a herniated lumbar disc. ${ }^{2,3}$ When bladder symptoms or progressive motor weakness are present, surgery is carried out as an emergency. In the absence of these symptoms $75-90 \%$ of patients with acute sciatica due to a protruded lumbar disc experience resolution of symptoms without surgery. ${ }^{1,4,5}$

The spontaneous disappearance of a herniated lumbar disc has been recognised with the widespread use of magnetic resonance imaging (MRI) ${ }^{6,7}$ To reiterate the point this report describes one such case of a massive disc prolapse which resolved spontaneously and was accompanied by complete relief of symptoms.

\section{CASE REPORT}

A 45-year-old woman was seen in the neurosurgery outpatient clinic with a 9-month history of low backache and bilateral sciatica in the L5 dermatome. Her pain was exacerbated by sneezing, coughing, and moving about. She did not have any bowel symptoms. She gave a history of frequency and urgency but never had any episode of urinary incontinence.

Neurological examination revealed normal power, symmetrical reflexes, and intact sensation in both lower limbs. Straight leg raise test was $90^{\circ}$ bilaterally.

An MRI scan of the lumbosacral spine revealed a large central disc at the L4/5 level (Figure 1). As the patient's symptoms were already beginning to improve, conservative management was pursued. The patient was reviewed after 2 months and her symptoms had completely resolved. A repeat MRI of the lumbar spine showed no major disc herniation or nerve root compression, and the disc prolapse that was present on the previous scan had completely disappeared (Figure 2).

\section{DISCUSSION}

The management of herniated lumbar discs may 
involve non-operative and operative treatments. The initial treatment is non-operative and includes continued activity, analgesia, and physiotherapy. There are many options for surgery including standard discectomy, microdiscectomy, percutaneous discectomy, or laser discectomy. The microdiscectomy provides similar results to the standard discectomy, but, as yet, there is not enough evidence to draw firm conclusions on the percutaneous or laser techniques.'

The question of whether surgery is better than conservative treatment remains unclear. Overall, surgery is associated with a quicker relief of symptoms in the short term; however, there is little evidence available to suggest that surgery is better than conservative treatment in longer term. ${ }^{1,3,9-11}$ The evidence that spontaneous resolution of a herniated disc occurs strengthens the role of a trial of conservative treatment in the absence of cauda equina syndrome before surgical intervention is undertaken.

The mechanism proposed for the reduction in the size of the herniated disc is an absorptive process that relies on neovascularisation and infiltration by inflammatory cells such as macrophages, granulocytes, and lymphocytes. ${ }^{12}$ It is also recognised that greater resorption of herniated discs occurs when there is a sequestered fragment. ${ }^{13,14}$

It is possible that this phenomenon of disappearing discs occurs more frequently. These cases are probably not detected because few patients have MRI examinations after the resolution of their symptoms. It is important to be aware that spontaneous resolution of herniated discs occurs, so that patients can be reassured and the role of conservative treatment can be emphasised.

\section{Consent}

The patient has consented to the publication of this report

\section{Acknowledgements}

With thanks to Mrs Debbie Doherty of the Department of Neurosurgery, University Hospital of Coventry and Warwickshire

\section{Competing interests}

The authors have stated that there are none.

\section{Discuss this article}

Contribute and read comments about this article on the Discussion Forum: http://www.rcgp.org.uk/bjgp-discuss

\section{REFERENCES}

1. Gibson JN, Waddell G. Surgical interventions for lumbar disc prolapse. Cochrane Database Syst Rev 2007; 2: CD001350.

2. Jönsson B, Stromqvist B. Neurologic signs in lumbar disc herniation: preoperative affliction and postoperative recovery in 150 cases. Acta Orthop 1996; 67(5): 466-469.

3. Weinstein JN, Tosteson TD, Skinner JS, et al. Surgical vs nonoperative treatment for lumbar disk herniation: the Spine Patient Outcomes Research Trial (SPORT) observational cohort. JAMA 2006; 296(20): 2441-2450.

4. Komori $\mathrm{H}$, Shinomiya $\mathrm{K}$, Nakai $\mathrm{O}$, et al. The natural history of

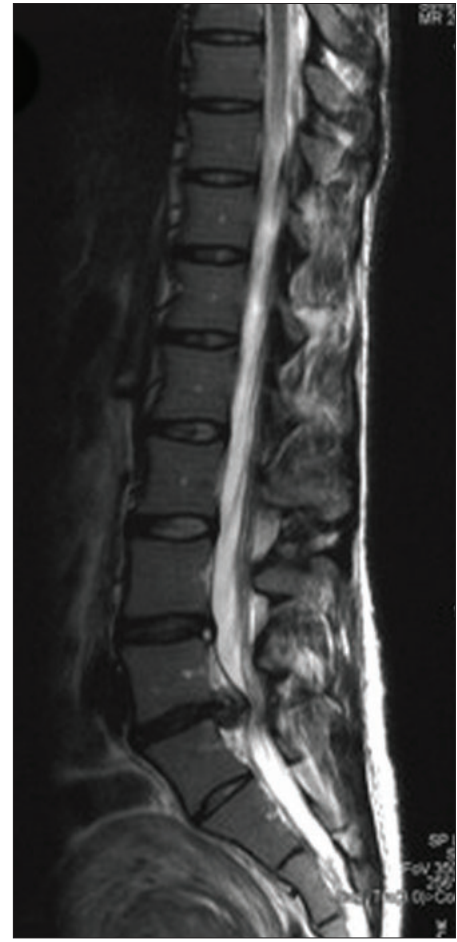

Figure 1. Sagittal T2 weighted images showing a large central disc protrusion.

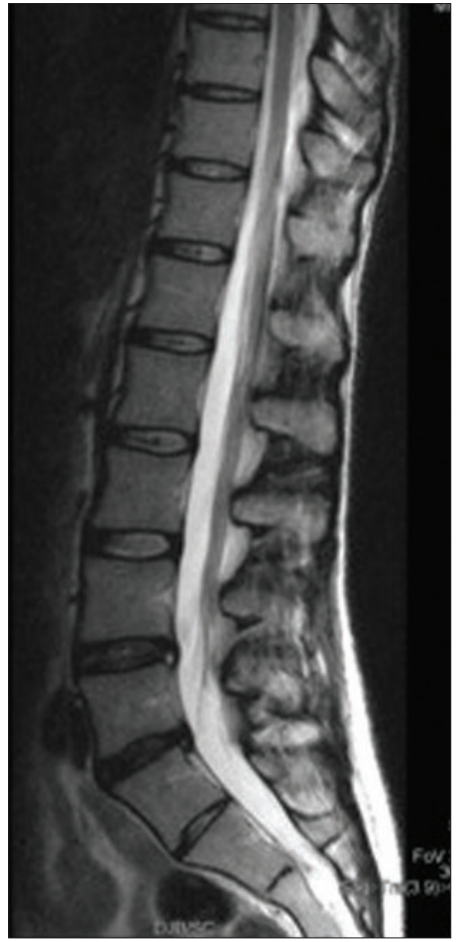

Figure 2. Follow up MRI scan 5 months later showing complete disappearance of the herniated lumbar disc. herniated nucleus pulposus with radiculopathy. Spine 1996; 21(2): 225-229.

5. Vroomen PC, de Krom MC, Knottnerus JA. Predicting the outcome of sciatica at short-term follow-up. Br J Gen Pract 2002; 52(475): 119-123.

6. Ellenberg M, Reina N, Ross M, et al. Regression of herniated nucleus pulposus: two patients with lumbar radiculopathy. Arch Phys Med Rehabil 1989; 70(12): 842-844.

7. Keskil S, Ayberk G, Evliyaoğlu C, et al. Spontaneous resolution of 'protruded' lumbar discs. Minim Invasive Neurosurg 2004; 47(4): 226-229.

8. Deyo RD, Weinstein JN. Low back pain. N Eng J Med 2001; 344(5): 363-370.

9. Van Tulder MW, Koes B, Seitsalo S, Malmivaara A. Outcome of invasive treatment modalities on back pain and sciatica: an evidence-based review. Eur Spine J 2006; 15(suppl 1): S82-S92.

10. Deyo RA. Back surgery who needs it? N Engl J Med 2007; 356(22): 2239-2243.

11. Peul WC, van Houwelingen HC, van den Hout WB, et al. Leiden-The Hague Spine Intervention Prognostic Study Group. Surgery versus prolonged conservative treatment for sciatica. $N$ Engl J Med 2007; 356(22): 2245-2256.

12. Ito T, Yamada M, Ikuta F, et al. Histologic evidence of absorption of sequestration-type herniated disc. Spine 1996; 21(2): 230-234.

13. Ahn SH, Ahn MW, Byun WM. Effect of the transligamentous extension of lumbar disc herniations on their regression and the clinical outcome of sciatica. Spine 2000; 25(4): 475-480.

14. Ahn SH, Park HW, Byun WM, et al. Comparison of clinical outcomes and natural morphologic changes between sequestered and large central extruded disc herniations. Yonsei Med J 2002; 43(3): 283-290. 